\title{
High Response and Precision Control of Electronic Throttle Controller Module without Hall Position Sensor for Detecting Rotor Position of BLDCM
}

\author{
Sang-Hun Lee*and Jin-Woo Ahn**
}

\begin{abstract}
This paper describes the characteristics of Electronic Throttle Controller (ETC) module in BLDC motor without the hall sensor for detecting a rotor position. The proposed ETC control system, which is mainly consisted of a BLDC motor, a throttle plate, a return spring and reduction gear, has a position sensor with an analogue voltage output on the throttle valve instead of BLDC motor for detecting the rotor position. So the additional commutation information is necessarily needed to control the ETC module. For this, the estimation method is applied. In order to improve and obtain the high resolution for the position control, it is generally needed to change the gear ratio of the module or the electrical switching method etc. In this paper, the 3-phase switching between successive commutations is adapted instead of the 2-phase switching that is conventionally used. In addition, the position control with a variable PI gain is applied to improve a dynamic response during a transient period and reduce vibration at a stop in case of matching position reference. The mentioned method can be used to estimate the commutation state and operate the highprecision position control for the ETC module and the high response characteristics. The validity of the proposed method is examined through the experimental results.
\end{abstract}

Keywords: Electrical throttle control, High-precision position control, Commutation estimation method

\section{Introduction}

In automotive traditional engines, the air coming into the intake is manifold, so the power is generated strongly depending on the angular position of a throttle valve.

In traditional systems, the throttle position is actuated by a mechanical link with the accelerated pedal, directly operated by the driver.

But in recent years an electronic throttle is increasingly being used in automotive engines in order to provide implementation of engine-based vehicle dynamics systems and the increasing requirements in terms of emissions control, drivability and safety have led to the development drive by wire. Automatic air flow control requires the additional actuators: for example, step motor, dc motor and BLDC.

In case of BLDC motor among them, it has advantages of reliability and higher performance although it has a slightly high production cost.

\footnotetext{
* Intelligent Automotive Research Team, DMI, Korea (1shdmi@naver.com)

** Department of Mechatronics Engineering, Kyungsung University, Busan 608-736, Korea(jwahn@ks.ac.kr)

Received 08 February 2013 ; Accepted 20 February 2013
}

Generally, an electronic throttle control system should meet the following requirements in a view of engineering practice under the sensor-based control system. Settling time of the position control system should be fast for any reference step change. The steady-state error should be less than 0.1 degree and no overshoot of the step response is allowed: this requirement is particularly important for the large signal mode in order to avoid hitting the mechanical stops at the maximum position. Low level of vibration in the throttle position signal and the commanded signal is required in order to avoid excessive potentiometer and transmission wear and motor losses. Robustness of the control system with respect to variations of process parameters is needed, which can be caused by production deviations, variations of external conditions and aging. In order to satisfy the requirements on fast and accurate throttle response, the linear controller is designed well for the large signal operating mode and the friction influence needs to be considered for the small signal operating mode. (Carlo Rossi, et al., 2000 ; Prechlaner, et al., 2001)

This can be usually done either by improving the electronic throttle mechanical/electrical design or by applying a compensation algorithm. 
This paper describes the characteristics of ETC module using BLDC motor without the hall sensor for detecting a rotor position. In addition, the electronic throttle is a BLDC servo drive which has 3 level cascaded control structures and 3 phase excitation method. The outer position controller is designed as a PI controller with the variable gains based on speed difference for the high performance at the steady sate and transient period. The inner current loop with a PI controller is used to develop a maximum torque for tracking a speed command. The validity of the proposed method is examined by experimental test.

\section{Control of ETC Drive System}

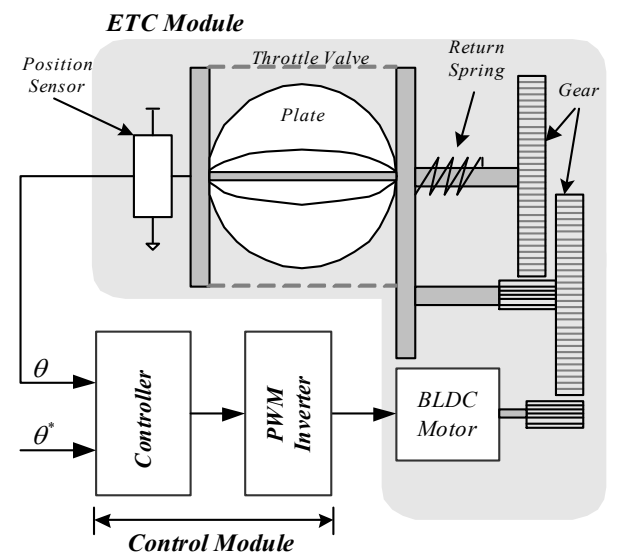

Fig. 1. The conceptional ETC Module

Fig.1 shows the conceptual electronic throttle controller module. It is mainly composed of BLDC motor, a throttle plate, a return spring, a reduction gear and position sensor with an analogue voltage output (i.e. potentiometer) on the throttle valve instead of BLDC motor for detecting rotor position.

The throttle plate motion is constrained by a return spring that returns the plate into its initial position in case of power supply failure. In general, the electronic throttle body has limp-home position, thus allowing the driver to limp the vehicle home. But the applied system has the bypass of the throttle valve whose section is regulated through the solenoid-type valve at the mentioned condition. So there is not nonlinear characteristic by the limp home.

\subsection{Linear model of BLDC motor}

Fig.2 shows the equivalent circuit of BLDC motor with inductance $\left(L_{x}, x=a, b, c\right)$, resistance $(R)$ and back
EMF $\left(e_{x}, x=a, b, c\right)$ proportional to the rotation speed of motor.

The corresponding equation is as follows.

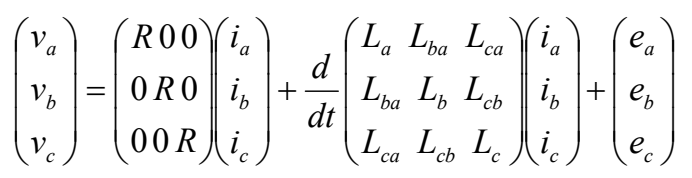

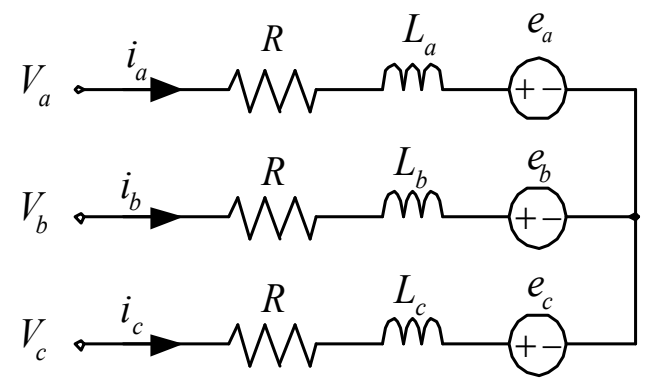

Fig. 2. Equivalent circuit of BLDC motor

where

$\begin{array}{ll}L_{a}=L_{b}=L_{c}=L_{s} & : \text { self inductance } \\ L_{a b}=L_{b c}=L_{c a}=M & : \text { mutual inductance } \\ i_{a}, i_{b}, i_{c} & : \text { phase current } \\ v_{a}, v_{b}, v_{c} & : \text { phase voltage }\end{array}$

If considering self-and mutual inductance in eq. (1),

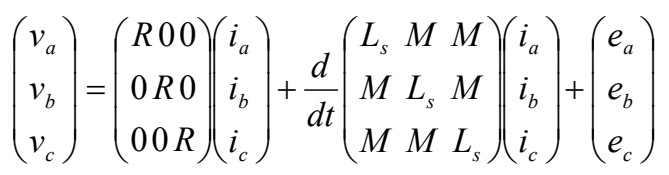

And then substituting $i_{a}+i_{b}+i_{c}=0$ in eq. (2)

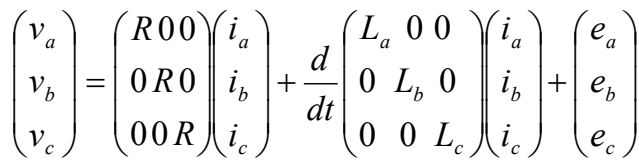

$$
\begin{aligned}
& \text { where } L=L_{s}-M
\end{aligned}
$$

Therefore the output and torque equation are expressed as follows.

$$
P_{\text {out }}=e_{a} i_{a}+e_{b} i_{b}+e_{c} i_{c}
$$

$$
T_{e}=\frac{e_{a} i_{a}+e_{b} i_{b}+e_{c} i_{c}}{\omega_{\text {mech }}}
$$

where $\omega_{\text {mech }}:$ mechanical speed 


\subsection{Control of ETC module}

In General, two phase excitation method is used to operate the ETC Drive System using BLDC Motor in which the commutation of current depends on the back-EMF of BLDC motor including position information of rotor.

Therefore it is essential to detect the rotor position with/without a hall sensor and then sequentially to conduct the phase current as shown in Fig.3.

In this paper, the ETC module has a position sensor with an analogue voltage output on the throttle body instead of BLDC motor for detecting rotor position. So an indirect estimation method is needed to control the ETC module. Fig.4 and 5 show the conduction path and a sensor output when BLDC motor is driven by the change of switching state at two phase excitation.
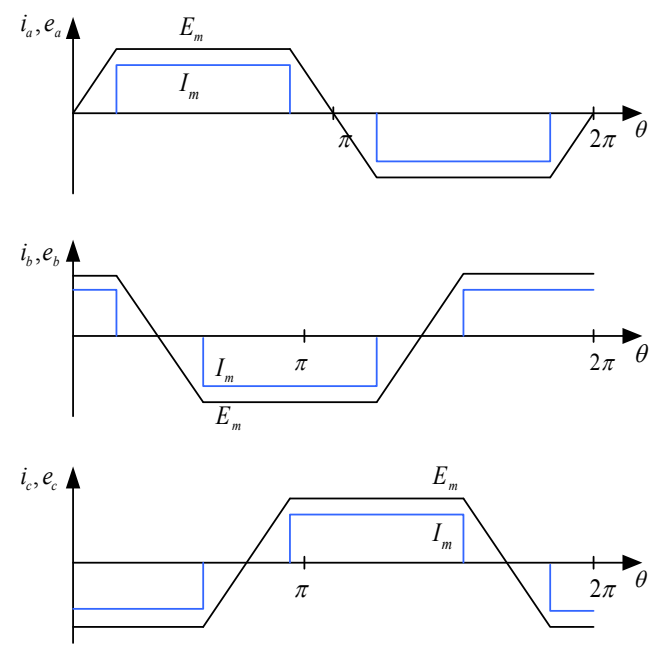

Fig. 3. Back-EMF vs. Phase Current of BLDC

The mentioned estimation method is to use the steplike position sensor output based on the $\mathrm{A} / \mathrm{D}$ conversion value of containing next or previous switching state indirectly to determine the phase commutation. Therefore if there is any position of rotor, it is possible to obtain the position information for commutation through the discrete output signal of throttle position sensor. In case of two phase excitation, however, the position control is operated by 60 degree in electrical angle and so it is needed to raise the reduction ratio of module or pole number of motor for a high precision control.

But these changes can result in decreasing a dynamic response of the module, although they directly increase the resolution of position control. In addition, the mentioned method has a burden of increasing the rotation speed of motor at no-load condition or/and the developed torque at lock condition for improving dynamic response.

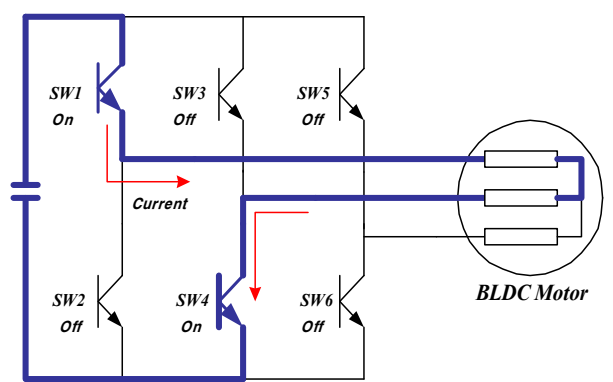

(a) Conduction Path $1(\mathrm{SW} 1 \rightarrow \mathrm{SW} 4)$

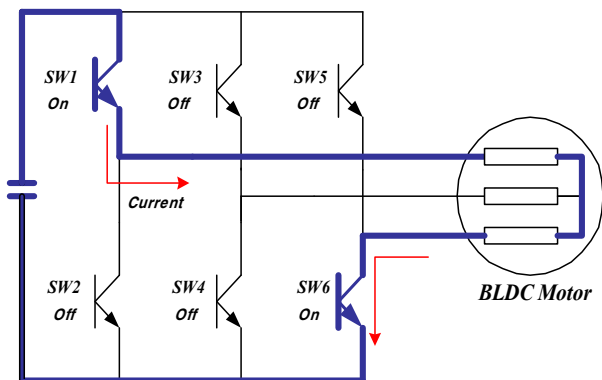

(b) Conduction Path $1(\mathrm{SW} 1 \rightarrow \mathrm{SW} 6)$

Fig. 4. Conduction path in 2 phase excitation

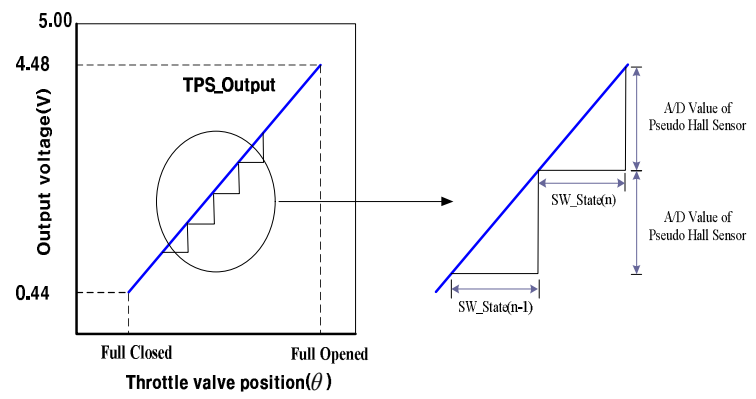

Fig. 5. TPS voltage output in 2 phase excitation

\section{The Proposed Control Method}

In this paper, it is applied to the three phase excitation method instead of the two phase excitation, the common method of operating BLDC motor, as shown in fig. 6 that can improve the high resolution and precision without the additional change of the mechanical or electrical specification design, for example, a reduction ratio and pole number of BLDC motor.

In General, two phase excitation method has the higher average torque and the lower usage of torque than three phase excitation. But because the position control of motor can be operated in the only energized stator windings in case of two phase excitation method, it is difficult to do high resolution position control of motor between the energized windings. 
On the other hand, the applied method can achieve a high-precision control at any position and the shape of phase current is not rectangular waveform but a sinusoidal one.

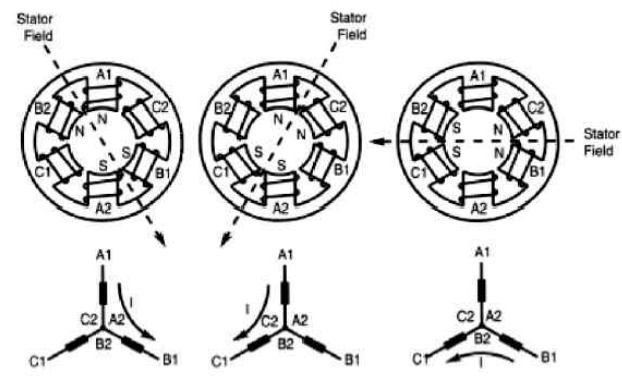

(a) 2- phase excitation method

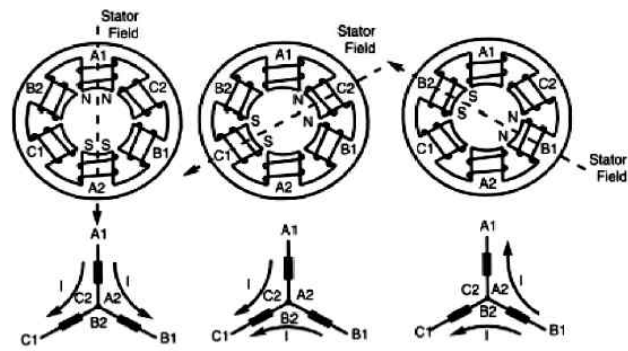

(b) 3-phase excitation method

Fig. 6. Comparison of excitation method

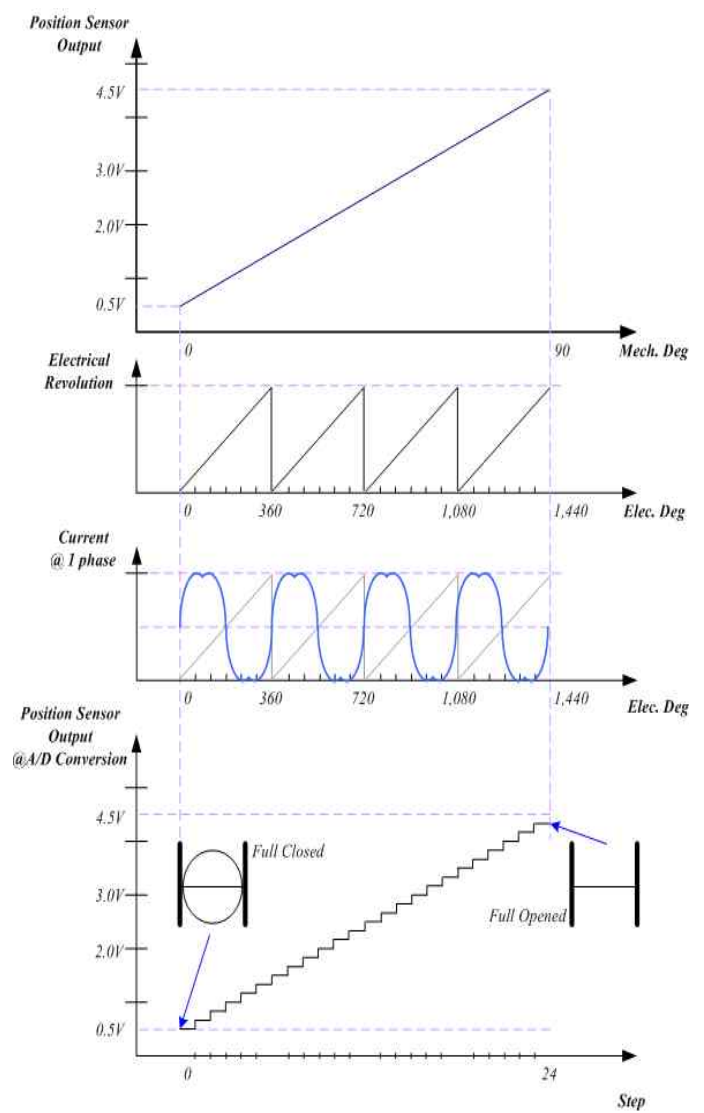

Fig. 7. Position output \& current waveform

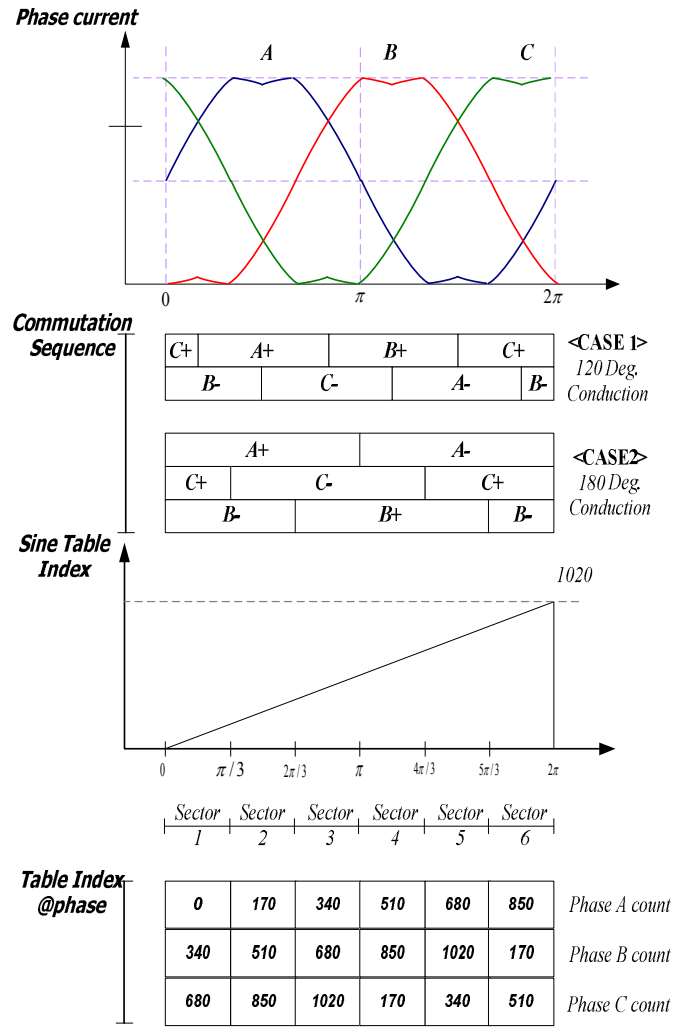

Fig. 8. Table composition for high-precision position control

Fig.7 shows that the correlation of throttle valve position output and the conducted current waveform per mechanical cycle, of which the throttle plate moves from the full-closed state ( 0 degree) to the full-open state $(90$ degree) or to the contrary and also an electrical cycle has 4 times of a mechanical one considering BLDC motor with 6 slots and 4 poles.

In the mentioned scheme, a sine table with 1020 index per electric cycle as shown in fig. 8 is used to conduct the phase current at operation and through the look-up table the position resolution for high precision control can be improved.

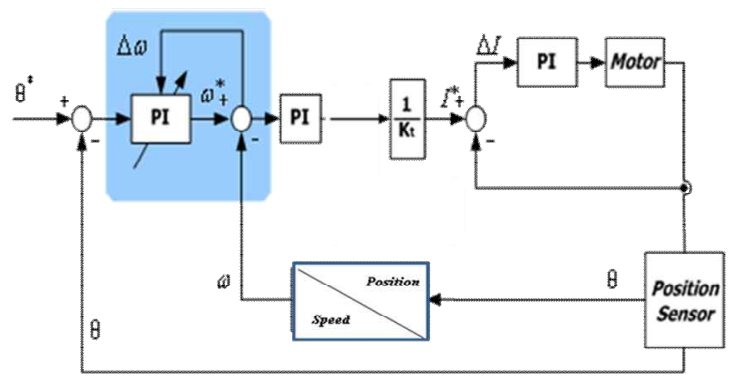

Fig. 9. Control block diagram 
Fig.9 shows the control block diagram with 3 level cascaded control structures. It is mainly composed of current control, speed control and position control loop with a variable PI gain.

The inner current loop with a PI controller per 100 usec is used to develop a maximum torque for tracking a speed command. It is needed that the gain scheduling, as shown in fig.10, is applied to control motor for high response during transient period and to cancel out vibration at a settling zone including a stop state in case of matching position reference. For this, the speed difference according to the position command is used to change $\mathrm{P}$ gain and I gain respectively.

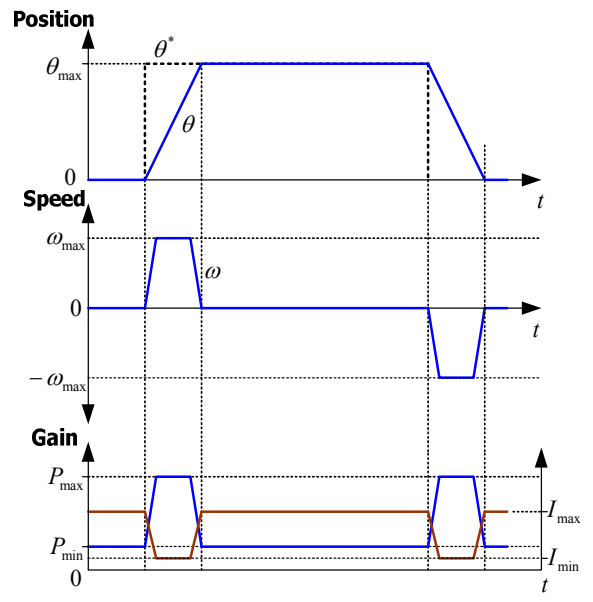

Fig. 10. PI gain scheduling scheme for high precision and high response position control

\section{Designed System}

Fig.11 shows the overview of the electronic throttle control system. From fig.11, it may be seen that the control system consists of three parts.

The first part is composed of the inverter that has a shunt resistor for current feedback control and six switching device. The second is the electronic throttle body that has BLDC motor, a return spring, and a position sensor and reduction gear. Finally there are the processor and user interface blocks for the control part. In addition, TMS320F2812 is used for the control processor and the built-in 12 bit A/D converter is used for the position control and the inner current control, respectively.

The inverter can be operated at the rated voltage of $12 \mathrm{~V}$ and the rated current amounts to about $3 \mathrm{~A}$ for providing the output power of $50 \mathrm{~W}$. Table 1 shows the main specification of ETC control system and fig. 12 is the prototype system for exercising the proposed algorithm.

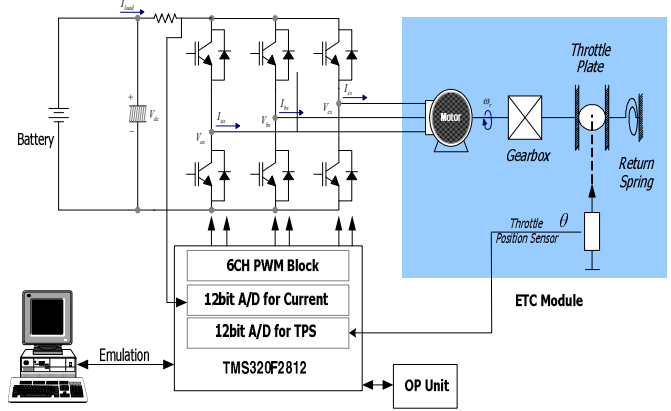

Fig. 11. System composition

Table1. Main specification of ETC control system

\begin{tabular}{|c|c|}
\hline Rated Voltage[V] & 12 \\
\hline Rated Current[A] & 2.5 \\
\hline Switching freq. [kHz] & 10 \\
\hline Pos. sensor output [V] & $0.44(\mathrm{~min}) \sim 4.48(\mathrm{max})$ \\
\hline BLDC motor & 6slot/ 4pole \\
\hline Motor speed[rpm] & Max. 6,000 \\
\hline Reduction ratio & $16: 1$ \\
\hline
\end{tabular}

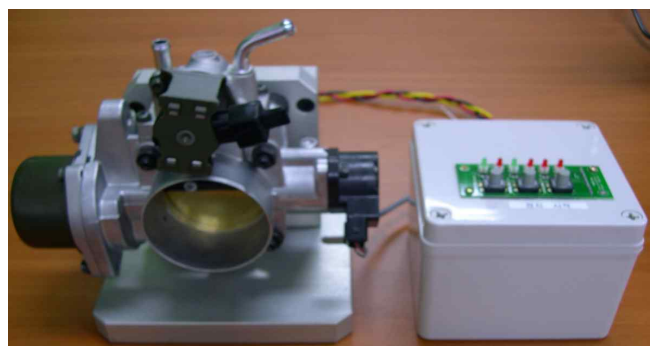

Fig. 12. External view of the prototype system

\section{Experimental Results}

Fig.13 shows the 3 phase switching waveform when the electronic throttle is periodically operated towards up or down direction.

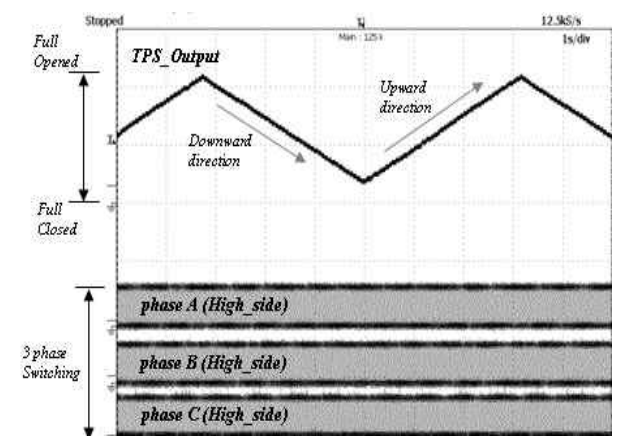

Fig.13. TPS output \& switching waveform of 3 phase excitation 
Fig.14 shows a smooth throttle position trajectory and the commutation phase current. In the first step command and the second ramp command respectively, the phase current has 4 cycles until the throttle valve moves from the closed state to the open state. And at the change of position command, the direction of phase current is reversed as shown.

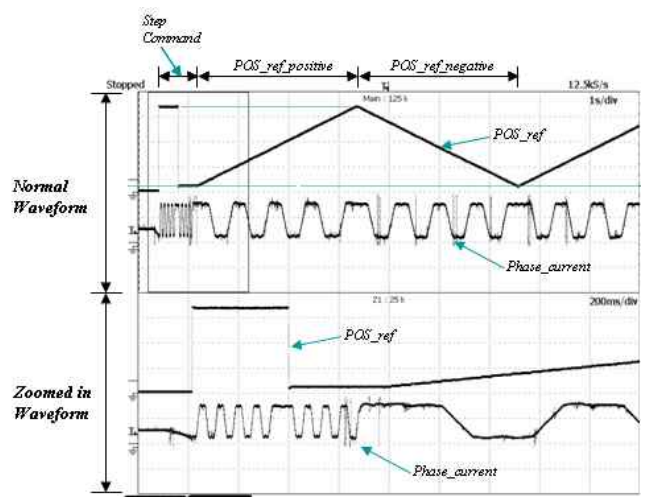

Fig. 14. Reference position vs. phase current

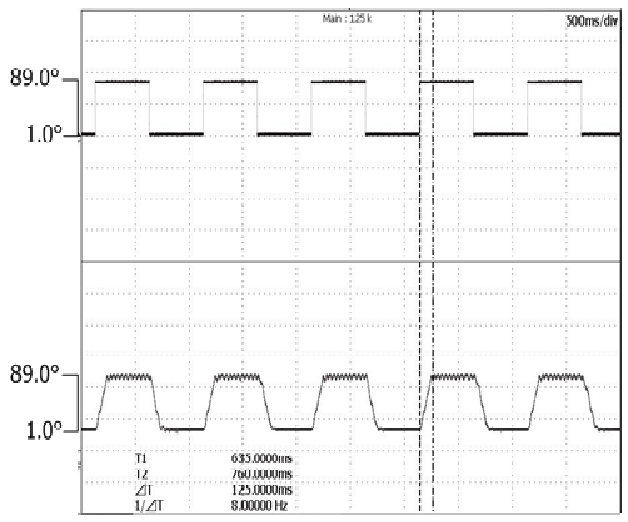

(a) Step responses without a variable PI controller

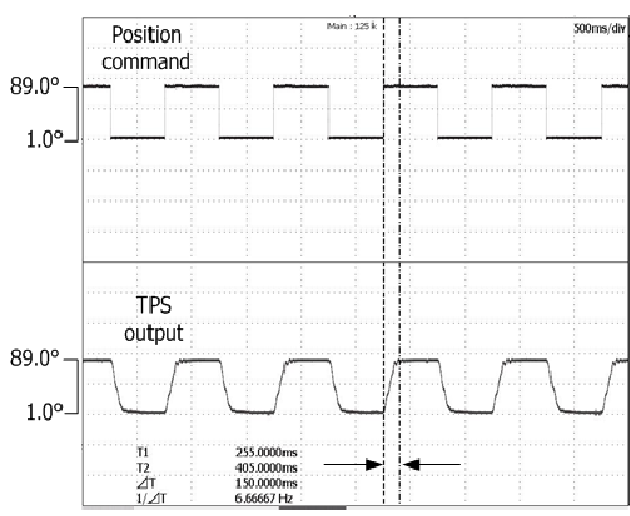

(b) Step responses with a variable PI controller

Fig. 15. Experimental responses with and without a variable PI controller
Fig.15 illustrates the step response characteristics for different small step changes of reference position. The prototype controller has a minimum position resolution of 0.128 degree due to $\mathrm{A} / \mathrm{D}$ resolution and the noise level in the control board. In a small difference of step command, it has some delay to reach the target position because of some residual effects and the friction influence.

Fig.16 demonstrates that the application of a variable PI controller for position control results in a significant reduction when the throttle valve reaches the target position through the two extreme positions being set to 1.0 degree and 89 degree, respectively, for safety reasons. A position response is shown in fig 16 (b), $150 \mathrm{msec}$.

\section{Conclusion}

This paper proposes the characteristics of ETC module using BLDC motor without the hall sensor for detecting a rotor position.

In the prototype system, it is used the cascaded 3 level cascaded control structure and 3 phase excitation method. It enables the characteristics of the position control with a minimum position resolution of 0.128 degree and a response time of $150 \mathrm{~ms}$. In addition, the use of variable PI controller has an effect on the reduction of vibration and the improvement of response. The experimental results confirm the feasibility of the proposed approach.

\section{Acknowledgement}

This work was supported by the Ministry of Knowledge Economy. The technical support and cooperation are also much appreciated.

\section{References}

[1] S.H.Lee, S.B.Lee and C.H.Park, "A Study on a Signal Processing Method for the Hall Sensorless Position Control of ETC Control System Using a BLDC motor", Transactions of KSAE, Vol.16, No 5, pp.92-99, 2008

[2] Mrdjan Jankovic and Steve W,. Magner, "Power Output Monitoring for Vehicles Equipped with Electronic Throttle", Proceedings of the American Control Conference Arlngton, VA June 25-27, 2001

[3] Carlo Rossi, Andrea Tilli and Alberto Tonielli, "Robust Control of a Throttle Body for Drive by Wire Operation of Automotive Engines", IEEE Transactions on Control Systems Technology, Vol.8, No.6, Nov., 2000

[4] Pechlaner, A. and S. BjOrn, "Electronic Throttle Control with Contactless Position Sensor and Smart Power Full-Bridge Controls", SAE 2001 World Congress, Detroit, Michigan, 2001 
[5] P.C. Krause, "Analysis of Electronic Machinery and Drive Systems", $\quad 2^{\text {nd }}$ edition, pp. 109-136, McGraw-Hill, 1987

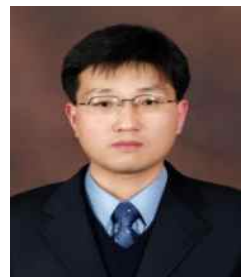

SangHun Lee received the Ph.D degree from Pusan National University, Pusan, Korea; From 2002 to 2006 he was with LG-OTIS company. Since April 2006 he is Intelligent Automotive Research team manager at Deagu Machinery Institute of Components and Materials. His research interests are in power electronics, electric traction and energy conversion.

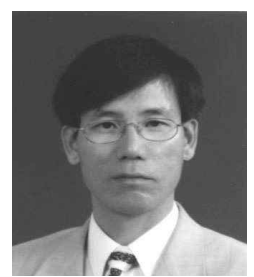

Jin-Woo Ahn received his B.S., M.S., and Ph.D. degrees in Electrical Engineering from Pusan National University, Pusan, Korea, in 1984, 1986, and 1992, respectively.

He has been with Kyungsung University, Busan, Korea, as a professor in the Department of Mechatronics Engineering since 1992. He was a visiting researcher in the Speed Lab at Glasgow University, U.K., a visiting professor in the Dept. of ECE and WEMPEC at the University of Wisconsin-Madison, USA, and a visiting professor in the Dept. of ECE at Virginia Tech from July 2006 to June 2007. He was the director of the Advanced Electric Machinery and Power Electronics Center and President of Korea Regional Innovation System Association. $\mathrm{He}$ also has been the director of the Smart Mechatronics Advanced Research and Technology Institute since. 2008 and the Senior Easy Life Regional Innovation System since 2008, which are authorized by the Ministry of Knowledge Economy, Korea. He is the author of five books including SRM, the author of more than 150 papers and has more than 20 patents. His current research interests are advanced motor drive systems and electric vehicle drives. He has been the Editor-in-Chief of JICEMS, Chairman of ICEMS2013 and IEEE ICIT 2014.

Dr. Ahn received several awards including the Best Paper Award from the Korean Institute of Electrical Engineers in 2002 and 2011, The Korean Federation of Science and Technology Society in 2003, Korean Institute of Power Electronics in 2007, Park Min-Ho Prize in 2009, Busan Science \& Technology Prize in 2011 and Ministerial Citation of Ministry of Knowledge Economy in 2011, ICEMS2012 Outstanding Paper Reward in 2012 respectively. $\mathrm{He}$ is a Fellow of the Korean Institute of Electrical Engineers, a member of the Korean Institute of Power Electronics and a senior member of the IEEE. 